\title{
ENFERMEDAD Y LITERATURA EN HORACIO QUIROGA
}

\author{
Gustavo Pis Diez
}

Historia de la Medicina, Facultad de Medicina, UCM.

Cierta vez le preguntaron a Quiroga cómo hacía sus cuentos. «No lo sé -respondió- sospecho que los construyo como aquel que fabricaba los cañones haciendo ante todo un largo agujero que, luego, rodeaba de bronce»

José M. Delgado y Alberto Brignole Vida y obra de Horacio Quiroga Montevideo: Claudio Garcia, 1939.

\section{RESUMEN}

Se intenta abordar el uso metafórico de la enfermedad en la narrativa de Horacio Quiroga, postulando que lejos de ser accidente o azar, expresa la fatalidad que preside la vida de sus personajes. Enigma, soledad y destierro son los temas de las tres historias que se analizan, y que se materializan en alteraciones orgánicas, mentales o una mezcla de ambas. Asimismo, en tanto literatura, evita la tautología al arrojar siempre nuevos significados a nuevas lecturas.

\section{SUMMARY}

This study aims to examine the metaphorical use of disease in the narrative of Horacio Quiroga. It postulates that disease, far from being by accident or chance, expresses tha fatality that determines the life of his characters. Enigma, loneliness and exile are the subjects of the three stories wich are analysed, and wich materialise into organic or mental alterations, or a mixture of both. Similarly, as regards literature, tautology is avoided as new meanings to new readings are put forward.

\section{INTRODUCCION}

Como toda obra de arte, la narrativa de Horacio Quiroga admite múltiples interpretaciones, ya que en tanto obra viva siempre ofrecerá nuevos significados a nuevos lectores, también. Esto es así pues más allá de la aparente ironía que encierra la respuesta del epígrafe, en el centro de sus cuentos está siempre ese insondable «aguje- 
ro» (esa nada, por tanto) de la que mana, silenciosamente, la historia que nos quiere contar y que hace que la obra «obre». Es por eso por lo que toda tarea analítica debe detenerse justo un paso antes del agujero y resistir la tentación de cerrarlo, invocando una preocupación central que le hubiera impulsado a escribir ${ }^{1}$. Esto no invalida, por supuesto, iluminar mediante el análisis una u otra de las dimensiones reconocibles en su obra; siempre que no perdamos de vista, reiteramos, que son momentos de una partitura que sigue su curso hasta alcanzar el silencio. Pues «en literatura -ha escrito Quiroga- el silencio es animador» ${ }^{2}$.

Probablemente la dimensión trágica de muchos de sus cuentos -esa pura imposibilidad kafkiana de todo y para todo, concomitante con la fatalidad de la experiencia que sobrellevó en su propia vida ${ }^{3}$ - sea de las más ricas de su obra. Y es ahí donde la enfermedad, lo anormal físico o mental, gravita ora como tema central de la narración, ora como desencadenante o posibilitante de la tragedia ${ }^{4}$. Pero aunque la dialéctica de la narrativa nos induzca a creer que la enfermedad es la «causa» del sufrimiento o infortunio de los personajes, la sensación más profunda es que no es tal; sino que, por necesidad, la vida (la existencia) de los hombres es así, y la alteración fatal -enfermedad o accidente- brota del mismo lugar del que lo hace la realidad entera.

1 Es conocida la declaración que hace Quiroga a Martinez Estrada acerca de los motivos que lo impulsan a escribir: «Y a propósito: valdría la pena exponer un día esta peculiaridad mía (desorden) de no escribir sino incitado por la economía. Desde los 29 o 30 años soy así. Hay quien lo hace por natural descarga, quien por vanidad; yo escribo por motivos inferiores, bien se ve. Pero lo curioso es que escribiera yo lo que fuere, mi prosa sería siempre la misma. Es cuestión entonces de palanca inicial o conmutador intercalado por allí: misterios vitales de la producción que nunca se aclararán.» Pero con frecuencia se omite lo que también le acaba de decir, unos párrafos más arriba, y que sitúa la cuestión en un plano bien distinto. «Este es el caso, que es el del artista de verdad. Verso, prosa: a uno y otra va a desembocar el sobrante de nuestra tolerancia psíquica. Pues vividas o no, las torturas del artista son siempre una. Relato fiel o amigo leal, ambos ejercen de pararrayos a estas cargas de alta frecuencia que nos desordena. MARTINEZ ESTRADA, E. (1966), El hermano Quiroga y cartas de Horacio Quiroga a Martinez Estrada, Montevideo, p. 154. La fecha de carta es 26-8-36.

2 Quiroga, H. (1993), La retórica del cuento. En: Horacio Quiroga, Todos los cuentos (Edición crítica a cargo de Napoleón Baccino Ponce de Léon y Eduardo Lafforgue para la colección «Archivos», n 26 del C.S.I.C), Madrid: ALLCA XXe. siècle-F.C.E, 1195-1196, p. 1195. Todas las transcripciones de la obra de Quiroga que se citan en este trabajo están extraídas de esta edición crítica.

3 En una carta anterior a la citada (del 25 de julio del mismo año), Quiroga le dice a Estrada: «Si, querido compañero. Y también tengo en la memoria una frase de Emerson, correlativa de aquella: `Nada hay que el hombre no pueda conseguir, pero tiene que pagarlo'.» Esta imposiblidad de eludir el sufrimiento se constituirá en algo valioso y, en palabras de Jitrik, en «la única arma que se posee para acercarse a las cosas con alguna coherencia.» JITRIK, Noé (1959), Horacio Quiroga. Una obra de experiencia y riesgo, Buenos Aires: Ediciones Culturales Argentinas, p. 58.

4 Sin caer en la tentación, tan común, de «explicar» la obra de un autor por su vida, o de justificar ésta por aquélla, aunque es innegable que están estrechamente relacionadas, no podemos dejar de señalar que cuando Quiroga tuvo conocimiento de que su mal era mortal por necesidad, se quitó la vida. Se puede ver una interesante aproximación a esta cuestión (que suscribimos) en STAROBINSKI, J., La relación crítica (psicoanálisis y literatura), Madrid, Taurus, 1974, p. 214. 
En este trabajo nos proponemos verificar la plausibilidad de lo dicho en tres historias correspondientes a las etapas de madurez de la producción quiroguiana ${ }^{5}$. «Los buques suicidantes» (1906) pertenece al libro Cuentos de amor de locura y de muerte, publicado por primera vez en 1917. «El desierto» (1923) aparecido en el libro homónimo de 1924 y «Los destiladores de naranjas» que vió la luz en 1923 y que integraría el volumen Los desterrados, de 1926, considerada la obra de plena madurez de Quiroga y donde su talento se despliega con mayor intensidad, elegancia y coherencia. Por supuesto, la enfermedad (lo patológico, mejor) aparece en una enorme cantidad de sus relatos y con una gran variedad de matices, expresada en un lenguaje de gran precisión técnica y adecuado a los conocimientos que la medicina científica poseía en las primeras tres décadas del siglo. Sabido es, además, el enorme interés que Quiroga profesó por el conocimiento científico y técnico 6 .

A la espera de un análisis exhaustivo y crítico del corpus narrativo quiroguiano, el criterio seguido en la elección de estas tres narraciones es el tipo, por así decirlo, de alteración que afecta a los protagonistas: predominantemente psíquico en «Los buques suicidantes» netamente físico por su origen, aunque con cruciales pasajes de alucinaciones en el «El desierto», y una mezcla de ambas características (el delirium tremens es causado por la intoxicación alcohólica, se sabe) en «Los destiladores de naranjas».

Horacio Quiroga nació en Salto (Uruguay) el 31 de diciembre de 1878. Vivió una vida tan intensa como lo mejor de su literatura, incluyendo una acumulación de muertes violentas de seres queridos inusual. Su padre, Prudencio, muere cuando el escritor contaba un año, al disparársele la escopeta de regreso de una excursión de caza. Su padrastro, Ascencio Barcos, no podrá soportar la invalidez y la afasia producidas por una hemorragia cerebral y se dispara una escopeta en el rostro, con el

5 Los cuatro períodos más o menos aceptados por críticos y biógrafos de este autor se distribuyen así: a) de iniciación literaria, aprendizaje del modernismo y estridencias decadentistas; se registra también una oscilación entre poesía y prosa. Se clausura con la publicación de El crimen del otro (1904); b) Con Cuentos de amor de locura y de muerte (1917) se cierra el segundo período, en el que su atención está puesta en el estudio de la técnica narrativa por un lado, y del ambiente misionero por otro. Este libro, el más rico y heterogéneo (Rodriguez Monegal) recoge también obras del período anterior; c) Hacia 1926 aparece Los desterrados, con lo que concluye el tercer período; es la plenitud de Quiroga y, para muchos, su última gran obra; d) en efecto, en 1935 aparecerá Más allá, conjunto de once relatos (cuatro de los cuales son anteriores a Los desterrados), que marcarán la «decadencia» del narrador. Entrecomillamos pues el juicio no es unánime al respecto. Véase LAFFORGUE, J. «Actualidad de Quiroga», en QUIROGA (1993), XXXV-XLIV. Actualmente estamos elaborando una tesis doctoral sobre la imagen de la enfermedad en la narrativa quiroguiana, vista desde una perspectiva antropológica amplia. Hasta donde sabemos, esta problemática no ha sido abordada con especificidad hasta el presente.

6 Con respecto al enorme interés que tenía Quiroga por todo lo que se relacionara con la ciencia (cuyo lenguaje permea toda su obra e incluso su correspondencia) véase SARLO, B. (1993) «Horacio Quiroga y la hipótesis técnico-científica»; y PUCCINI, D. (1993), «Horacio Quiroga y la ciencia». En: BACCINO PONCE DE LEON, N.; LAFFORGUE, J. (1993), 1274-1292, 1340-1359. 
único pie hábil que le quedaba. El joven Quiroga será el primero en acudir al oírse el disparo (noviembre de 1896).

En 1901 perderá, a causa de la fiebre tifoidea, a dos hermanos mayores, Prudencio y Pastora. El 5 de marzo de 1902 y mientras está examinando una pistola con la que su amigo Federico Ferrando piensa batirse a duelo, se le escapa un tiro que acaba con la vida de éste. Siete años después de un tormentoso noviazgo se casa con Ana María Cirés, el 30 de diciembre de 1909. Instalados en Misiones, nacen allí dos hijos, Eglé y Darío. Luego de seis años de tensa convivencia, las frecuentes depresiones de Ana María la llevan al suicidio. Muere el 14 de noviembre de 1915, luego de tres días de agonía plenos de arrepentimientos y reconciliaciones inútiles. Finalmente, no sólo Quiroga mismo sale voluntariamente al encuentro con la muerte (18 de febrero de 1937) cuando sabe que tiene cáncer de vejiga, sino que el mismo destino alcanzará a sus hijos mayores; Eglé se suicida en 1948 y Darío lo hará pocos años después.

Esta sucesión de muertes hallará eco en su narrativa, sin duda. Primero como una necesidad interna de su estilo modernista (como en la primera historia que analizamos), bajo el influjo de sus maestros: Poe, Baudelaire, Maupassant, Kipling, Dostoiewski. Más tarde será una posibilidad cierta de seres, humanos y no humanos, arrojados a una existencia inerme en la selva hostil, como en Los Desterrados. Tal vez Quiroga fue un desterrado, pero lo fue de sí mismo, un exiliado de la existencia al que un medio elemental, agresivo y peligroso como la selva misionera le permitió hacer lo mejor de su literatura. Una literatura donde la muerte, a fuerza de ser convocada, cede algo de su absurdo radical y se hace un poco más inteligible. En palabras de A. Visca fue «...un hombre que parece, al mismo tiempo, vivir buscándose a sí mismo e intentando fugarse de sí en todo instante, como si recubriera con mil máscaras el rostro verdadero...[y que] hunde su vida en la selva para encontrarse a sí mismo y la hunde también para olvidarse de sí».

Quiroga vivió su vida de adulto entre Buenos Aires y las provincias del Chaco (1904-05) y Misiones (1910-16 y 1932-36). Fue profesor de castellano y literatura, escritor profesional, juez de paz, diplomático y agricultor. Escribió cerca de ciento sesenta y seis cuentos, dos novelas, seis novelas cortas, dos obras de teatro, un libro de texto escolar (en colaboración), guiones de cine, artículos periodísticos y de crítica. Dejó también una copiosa correspondencia, que aún hoy no ha sido agotada por los estudiosos de su obra y que ha permitido componer, hasta cierto punto, la imagen del Quiroga interior.

Sus cenizas descansan en su Salto natal, en una urna que ostenta su rostro y está realizada en madera de Misiones. 


\section{LOS TEXTOS}

\subsection{Enfermedad y enigma: «Los buques suicidantes».}

En este relato, Quiroga toma un tema bastante conocido y trabajado en la literatura fantástica de su época ${ }^{7}$; los buques que navegan a la deriva y cuya tripulación ha desaparecido misteriosamente. En los primeros cuatro párrafos el tema es introducido por el narrador, quien discurre sobre los peligros que estos navíos sin gobierno suponen para la navegación nocturna y a los que imputa no pocas desapariciones de barcos. Acto seguido arriesga, maliciosamente, una explicación «natural» de estos sucesos, de manera tal que el contraste con lo que se relatará luego sea mayor.

\footnotetext{
«El principal motivo de estos abandonos de buque son sin duda las tempestades y los incendios que dejan a la deriva negros esqueletos errantes» 8
}

Para introducir, magistralmente y con dos palabras, excepciones a este tipo de causalidad:

\footnotetext{
«pero hay otras causas singulares entre las que se puede incluir lo acaecido al María Margarita...» ${ }^{9}$
}

Se sabe enseguida que luego de dos días de navegación y cuatro horas después de comunicarse normalmente con otro navío, el María Margarita dejó de responder a otros llamados y al ser abordado se lo halló desierto. Esta situación es descrita por Quiroga de manera cinematográfica, se podría decir:

«En el buque no había nadie. Las camisetas de los marineros se secaban a proa. La cocina estaba prendida aún. Una máquina de coser tenía la aguja suspendida sobre la costura, como si hubiera sido dejada un momento antes. No había la menor señal de lucha ni de pánico, todo en perfecto orden. Y faltaban todos. ¿Que pasó? ${ }^{10}$

La alusión a la máquina de coser es, sin duda, un toque de genialidad por parte de nuestro autor. Pocas cosas deben dar una sensación de extrañeza como una aguja

\footnotetext{
7 Como señala Baccino Ponce de León, es el mismo tema «que seduce a sus maestros Edgar Allan Poe, Guy de Maupassant, Joseph Conrad, Hope Hogdson y aún Hermann Melville; el buque fantasma que boga sin rumbo, devastador y enigmático, atrae con humor y algo de ironía a Horacio Quiroga, en este relato en el que confió afectuosamente». QUIROGA (1993), «Los buques suicidantes», 47-51, p. 51 (nota 2).

8 QUIROGA (1993), p. 47.

9 QUIROGA (1993), ibidem.

10 QUIROGA (1993), ibidem. 
suspendida sobre una costura, en un tiempo indefinido en el que el ordenamiento y secuencia normales de las cosas ha sido alterado. Se advierte, además, que la ausencia humana está doblemente señalada, al comienzo y al final del párrafo.

En este momento se participa al lector que el narrador aprendió esto en una travesía marítima y en una reunión en el puente, donde el capitán contaba a sus interlocutores esta historia. La respuesta a la interrogante con que termina el párrafo citado va a ser dada por otro relato, a cargo de uno de los pasajeros, apenas caracterizado por Quiroga, pues sólo se dice que es discreto. Es cierto, también, que no debe olvidarse la feroz economía narrativa a la que el escritor uruguayo sometía sus historias. Después de narrar el primer encuentro con un barco abandonado y la desaparición de los ocho marineros que habían quedado a cargo del gobierno del mismo, el pasajero relata su propia experiencia en aquél, aumentando la espiral de tensión del relato.

\footnotetext{
«Como ustedes comprenderán, el terror supersticioso de nuestra gente llegó a su colmo. A la larga se animaron a llenar vacío, y yo fuí con ellos. Apenas a bordo, mis nuevos compañeros se decidieron a beber para desterrar toda preocupación. Estaban sentados en rueda, y a la hora la mayoría cantaba ya» ${ }^{11}$.
}

De inmediato, Quiroga nos va a deslizar, insensiblemente, de lo normal a lo anormal, a una situación de extrañamiento, que no obstante, no interrumpe la naturalidad de la narración y que no quedará sin un intento de explicación. Esta explicación vendrá dada con categorías y términos de la psicología de la época, lo que no hace más que aumentar la ambigüedad y misterio de la situación. Como los grandes escritores, el uruguayo sabía perfectamente que lo extraño es lo cotidiano mismo apenas modificado, si se lo sabe ver, claro, y no tanto lo que le trastorna. El lector tiene la sensación que la historia queda suspendida en el aire, como un acorde imperfecto. Vale la pena transcribir el párrafo en el que se produce la primera muerte:

\footnotetext{
«Llegó el mediodía y pasó la siesta. A las cuatro, la brisa cesó y las velas cayeron. Un marinero se acercó a la borda y miró el mar aceitoso. Todos se habían levantado, paseándose, sin ganas ya de hablar. Uno se sentó en un cabo arrrollado y se sacó la camiseta para remendarla, cosió un rato en silencio. De pronto, se levantó y lanzó un largo silbido. Sus compañeros se volvieron. El los miró vagamente, sorprendido también, y se sentó de nuevo. Un momento después dejó la camiseta en el rollo, avanzó a la borda y se tiró al agua. Al sentir el ruido, los otros dieron vuelta la cabeza, con el ceño ligeramente fruncido. Pero enseguida parecieron olvidarse del incidente, volviendo a la apatía común.»12
}

Uno a uno, los seis marineros se arrojan al agua sin que se registre la menor perturbación en los que iban quedando.

11 QuiRoga (1993), p. 49

12 Quiroga (1993), ibidem. 
«Entonces quedé solo, mirando como un idiota el mar desierto. Todos sin saber lo que hacían, se habían arrojado al mar, envueltos en el sonambulismo moroso que flotaba en el buque. Cuando uno se tiraba al agua los otros se volvían momentáneamente preocupados, como si recordaran algo, para olvidarse enseguida. Asi habían desaparecido todos y supongo que lo mismo los días anteriores, y los otros y los demás buques. Eso es todo» ${ }^{13}$.

Introduciendo un estado patológico vago, que sitúa simultáneamente fuera de los humanos, ya que «flotaba en el buque», y dentro de ellos, desde que los impulsa a arrojarse al mar, ( podría hablarse de monomanía, quizá) Quiroga logra no violentar el clima de absoluta naturalidad de lo sucedido hasta el momento. Pero a la vez introduce una honda perturbación en quienes lo escuchan y en los lectores, claro. Como decíamos más arriba, cuanto más natural, ordinario y cotidiano es el marco donde irrumpe una anomalía, más inquietud produce. Naturalmente, el personaje debe explicar por qué no corrió la misma suerte que $\operatorname{los} \operatorname{otros}^{14}$, y es interrogado sobre lo que sintió:

«Sí; un gran desgano y obstinación de las mismas ideas pero nada más. No se por qué no sentí nada más. Presumo que el motivo es este: en vez de agotarme en una defensa angustiosa y a toda costa contra lo que sentía, como deben de haber hecho todos y aún los marineros sin darse cuenta, acepté sencillamente esa muerte hipnótica, como si estuviese anulado ya» ${ }^{15}$.

Un expediente tan sencillo (y original a la vez) no puede ser aceptado tan fácilmente por una audiencia de la que se supone no carece de escepticismo. El calificativo de farsante, imputado al extraño pasajero por el desconfiado capitán, es replicado por otro pasajero quien sostiene que si hubiera sido tal, no habría podido dejar de pensar en lo que obsesionó al resto y se hubiera arrojado al agua también.

En lo que respecta al recurso explicativo mismo - una enfermedad rara, un estado mental morboso caracterizado por la idea persistente del suicidio- referido apenas como un «sonambulismo moroso» que conducía a una «muerte hipnótica», Quiroga es parco en explicaciones etiológicas, y todo lo que sabemos de los síntomas es lo relatado por el pasajero en los párrafos transcriptos. No deja de ser sorprendente, eso sí, la estrategia mediante la que evita ser vencido por el morbo. La aceptación del mal como expediente para poner en evidencia su carácter ilusorio, y en un mismo movimiento quitarle realidad y vencerle, más parece una actitud oriental que un recurso de terapéutica occidental de la época. Veamos que sucede en las otras historias.

\footnotetext{
13 Quiroga (1993), ibidem.

14 Jitrik hace un interesante parangón entre este relato y el mito de Teseo, en una reflexión sobre literatura y experiencia: el héroe siempre es sospechoso de cometer engaño, puesto que el enigma no lo ha vencido (devorado o matado). Es que quizá para él, agregamos, no hay enigma. JITRIK (1959), p. 63.

15 QUIROGA (1993), p. 50.
} 


\subsection{Enfermedad y soledad: «El desierto».}

El tema que parece preocupar a nuestro autor, en esta historia, es el de la precariedad de la existencia humana, si no es el de la soledad esencial que la acecha. Para esto imagina un cuento - con fuerte acento autobiográfico- en el que la muerte del protagonista deja en evidencia el desamparo en el que quedan sus pequeños hijos. Desamparo en el que ya estaban los personajes y cuyas coordenadas son la hostilidad de la selva, el aislamiento y la reciente viudez de Subercasaux, el protagonista. Como veremos es este contexto el que permite que un hecho relativamente menor desencadene la tragedia.

En la primera parte de la narración se describe la vida que el trío llevaba en Misiones (provincia del nordeste de Argentina donde transcurren casi todas las historias de Quiroga en las que el escenario es la selva) y el tipo de educación -poco ortodoxa- que recibían los niños y que se centraba en saber valerse por sí mismos. $\mathrm{Si}$ bien la ausencia de la figura femenina se echa en falta, Subercasaux parece bastarse con las tareas de la casa, que se agregaban a las de su trabajo en el monte. Es en medio de la descripción de la vida cotidiana, tranquila, natural, donde van a surgir insensiblemente los elementos que compondrán la tragedia. Luego de hacer mención a la ingrata tarea de barrer el patio, (tarea que el protagonista consideraba exclusivamente femenina) Quiroga introduce, como al pasar, la causa externa de aquélla:

\footnotetext{
«En esa suelta arena sin remover, convertida en laboratorio de cultivo por el tiempo cruzado de lluvias y sol ardiente, los piques se propagaron de tal modo que se les veía trepar por los pies descalzos de los chicos»16.
}

Los piques son un tipo de pulga que prospera en lugares de tierra o cenizas suelta. Caminan empinados por la piel, la perforan con gran rapidez y llegan a la carne viva donde depositan sus huevos. Son parte inseparable de esa región y molestos compañeros de sus habitantes. Sabemos, por Quiroga, que salvo en rarísimos casos ( y justamente el relato es uno) estos parásitos no producen grandes complicaciones:

«la extracción del pique o la nidada no suelen ser molestos, ni sus heridas se echan a perder más de lo necesario. Pero de cien piques limpios hay uno que aporta una infección, y cuidado entonces con ella» ${ }^{17}$.

Con un relato neutral, casi científico, nuestro autor pasa de lo general a lo particular, humanizando en una espiral de tensión un elemento que pertenece al orden cósmico, impersonal, por así decirlo:

16 Quiroga (1993), p. 496.

17 QUIROGA (1993), ibidem 
«Subercasaux no lograba reducir una infección que tenía en un dedo, en el insignificante meñique del pie derecho. De un agujerillo rosa había llegado a una grieta tumefacta y dolorosísima que bordeaba la uña. Yodo, bicloruro, agua oxigenada, formol, nada había dejado de probar.

(...) Subercasaux reconocía que en otras condiciones de vida habría logrado vencer la infección, la que sólo pedía un poco de descanso. El herido dormía mal, agitado por escalofríos $\mathrm{y}$ vivos dolores a altas horas» ${ }^{18}$.

En esta pésima condición la atención de los pequeños se convirtió en una tarea titánica, que le decidió a salir en busca de personal de servicio. La densa descripción de este viaje, remontando un río que crecía por minutos, incluye un episodio que a la postre resultará fatal. Para utilizar la canoa con la que habitualmente viajaba por el río era menester quitarle el agua que se había acumulado en su interior:

«Metidos en el agua a ambos lados de la canoa baldeaban de firme. Subercasaux, en un principio, no se había atrevido a quitarse las botas, que el lodo profundo retenía al punto de ocasionarle buenos dolores arrancar el pie. Descalzóse, por fin, y con los pies hundidos como cuñas en el barro pestilente, concluyó de agotar la canoa...»19.

La infección generalizada subsiguiente - provocada por el contacto con «el barro pestilente»- irá venciendo las resistencias del protagonista y, paulatinamente, sumergiéndole en un delirio febril, cuyo contenido expresará la carencia y soledad en que se halla. Aparentemente pueril, este delirio encubre y descubre, a la vez, el ominoso desenlace hacia el que la narración se dirige:

«Como un sueño lejano, como una dicha de inapreciable rareza que alguna vez poseyó, se figuraba que podía quedar todo el día en cama, caliente y descansado, por fin, mientras oía en la mesa el ruido de las tazas de café con leche que la sirvienta -aquella primera gran sirvienta- servía a los chicos (...).

Y el día avanzaba, y el enfermo creía oír el feliz ruído de las tazas, entre las pulsaciones profundas de su sien de plomo. ¿Qué dicha oir aquel ruido!... Descansaría un poco, por fin...»20.

Por supuesto, el ensueño y la sensación de liberación que le aportaba es duramente quebrado por el reclamo de atención de los niños. A medida que la enfermedad avanza, Subercasaux tendrá menos fuerzas para dejar el lecho y los delirios que le colmaban de felicidad. Finalmente alcanzará la certidumbre de que ha llegado al final de su vida:

\footnotetext{
18 QUIROGA (1993), ibidem.

19 QUiROGA (1993), p. 499.

20 QUIROGA (1993), p. 500.
} 
«En el brazo derecho, desde el codo a la extremidad de los dedos, sentía ahora un dolor profundo. Quiso recoger el brazo y no lo consiguió. Bajó el impermeable, y vió su mano lívida, dibujada de líneas violáceas, helada, muerta. Sin cerrar los ojos pensó un rato en lo que aquello significaba dentro de sus escalofríos y del roce de los vasos abiertos de su herida con el fango infecto del Yabebirí, y adquirió entonces, nítida y absoluta, la comprensión definitiva de que todo él también se moría -que se estaba muriendo» ${ }^{21}$.

A su sufrimiento físico se agrega ahora, en un crescendo notable, la penuria de imaginar el desamparo en que quedarán sus hijos. Bordeando el melodrama, la narración culmina con el agravamiento final del personaje y una exhortación a los niños para que puedan sobrellevar su ausencia. Quiroga vuelve a intercalar aquí (como lo hiciera en «A la deriva») un pasaje en el que el enfermo experimenta una suerte de mejoría, o relajamiento, previo a la muerte:

«Abrió otra vez los ojos, y al abrirlos sintió que su cabeza caía hacia la izquierda con una facilidad que le sorprendió. No sentía ya rumor alguno. Sólo una creciente dificultad sin penurias para apreciar la distancia a la que estaban los objetos... Y la boca muy abierta para respirar.

-Chiquitos... vengan enseguida...

(...) Oiganme bien, chiquitos míos, porque ustedes son ya grandes y pueden comprender todo... Voy a morir, chiquitos... Pero no se aflijan ... Pronto van a ser ustedes hombres, y serán buenos y honrados...»22.

Resistiéndonos a la tentación -bastante difundida en la exégesis quiroguiana- de interpretar el cuento como un ejemplo de «la lucha del hombre contra la naturaleza», o de considerar a ésta como la causa del infortunio del protagonista ${ }^{23}$ podemos plantear que la infección mortal no es más que una manifestación del desamparo en que está Subercasaux, como una materialización de la soledad que el cuento trasunta desde el primer párrafo hasta el último. Quizá sea precisamente ahí donde está el genio de Quiroga; en poder dar forma literaria a un estado de ánimo (o del ser, que es lo mismo) por así decirlo, y desplegarlo en una narración simple, eficaz y verosímilmente «naturalista», pues aún las alucinaciones que la fiebre provoca en el protagonista tienen un contenido concreto. Aunque para nosotros, los lectores, signifiquen el agravamiento que lo conducirá a la muerte. Quiroga parece recuperar aquí la gravedad de la existencia, de toda existencia, como modulación de un cosmos que no conocemos. Como se ve, la selva puede ser el desierto.

1 QUIROGA (1993), p. 502.

2 QUIROGA, (1993), p. 503

23 Como sostiene, p. ej. I. FreIRIA en: «Sobre el proceso creativo en Horacio Quiroga: El desierto y El hombre muerto», Rev. de Estudios Hispánicos, 6, 1979, pp. 70-76. 
Veamos, por fin, cómo la enfermedad se presenta en su forma quizá más trágica, el destierro, en la tercera historia que comentaremos

\subsection{Enfermedad y destierro: «Los destiladores de naranjas»}

En este relato Quiroga propone la conjunción de unos peculiares personajes, patéticamente humanos, con una empresa cuasi inverosímil que, otra vez, terminará en tragedia para uno de ellos. Se trata de la fabricación de aceite esencial de naranja a partir de un complicado proceso de fermentación. El doctor Else es un joven y brillante biólogo sueco, que como nos informa el mismo Quiroga, fue contratado por el gobierno de Paraguay al comenzar el siglo, junto a otros profesores universitarios e industriales. Su tarea era organizar los laboratorios de los hospitales; tarea que al principio acometió con entusiasmo y fuerza. Pero no pudo escapar a la fatalidad que ronda a los personajes quiroguianos:

«Luego sus bríos se aduermen. El ilustre sabio paga al país tropical el pesado tributo que quema como en alcohol la actividad de tantos extranjeros, y el derrumbe no se detiene ya» ${ }^{24}$.

Después de una ausencia de quince o veinte años vuelve a aparecer en Misiones, exhibiendo como única finalidad en su vida -además de beber todo, claro está- hacer probar a quién lo desee la fortaleza del palo que utiliza como bastón. ${ }^{25}$ El segundo personaje es el manco Luisser, que ya ha sido introducido por el autor en un cuento anterior «Tacuara Mansión» publicado en 1920 y que luego pasó a integrar «Los desterrados». Este individuo parece ser una proyección de uno de los aspectos de la personalidad de Quiroga más notorios: la capacidad de acción y de inventiva ${ }^{26}$.

\footnotetext{
24 QUIROGA (1993), p. 682.

25 Esta extraña conducta, propia de alguien a quien podríamos llamar «loco», ilustra la profunda y amarga concepción de la normalidad que trasunta la narrativa quiroguiana. Iber Conteris lo ha visto bien: «Por «locura», al referirnos a la obra de Quiroga, debe entenderse algo más inclusivo, más próximo a la «normalidad» de la naturaleza humana. En realidad la necesidad que experimenta Quiroga es la de tocar los límites de esta naturaleza (...) El asunto en sí es siempre un pretexto para comunicar su más entrañable visión del universo; el fracaso de la empresa humana en todos sus órdenes. La frustración del amor, de la existencia y de la razón. El Dr. Else (...) experimenta este triple fracaso. CoNTERIS, I. «El amor, la locura, la muerte» (en: Flores, A. (1976), comp., Aproximaciones a Horacio Quiroga, Monte Avila Editores, Caracas, 151-156; p.153

26 Jitrik considera a la actividad como uno de los cuatro elementos básicos que permiten entender la narrativa del uruguayo; los otros tres son el sentido de la experiencia, la soledad y la muerte. JITRIK (1959), pp. 69-87).
} 
«Su orgullo, en verdad, consistía en un conocimiento más o menos hondo de todas las artes y oficios, en su sobriedad ascética y en dos tomos de «L'Enciclopedie» (...) planeaba siempre pequeñas industrias de consumo local, o bien dispositivos asombrosos para remontar el agua por filtración, desde el bañado del Horqueta hasta su casa (... ) había ensayado sucesivamente la fabricación de maíz quebrado (...) de mosaicos de bleck y arena ferruginosa, de turrón de maní y miel de abejas (...) de tintura de lapacho, precipitado por la potasa; y de aceite esencial de naranja...» 27 .

Junto a un tercer personaje, el químico Rivet -que también se ha convertido en un ex-hombre gracias al alcohol- se dan a la tarea de fabricar este aceite. Esta empresa es descrita en un tono entre grotesco y heroico, pues el complemento de los terribles esfuerzos que el manco hace para obtener ese producto es la perspectiva de inacabables borracheras gratuitas, a base del alcohol de naranja que la fermentación producía. De Else se nos informa que además de beber no hacía otra cosa que dar paseos:

«En todas las picadas se lo hallaba con sus zapatillas sin medias y el continente eufórico. Fuera de beber en todos los boliches y todos los días, de 11 a 16, no hacía nada más. Tampoco frecuentaba el bar, diferenciándose en esto de su colega Rivet»28.

Pero le une al químico francés el mismo trasunto de soledad y, más aún de desolación, en el que arrastraban sus existencias. Vale la pena transcribir el final del párrafo anterior, pues el talento de Quiroga le permite transmitir esto con imágenes difícilmente superables:

«Pero en cambio solía hallárselo a caballo, a altas horas de la noche, cogido de las orejas del animal, al que llamaba su padre y su madre con gruesas risas. Paseaban así horas enteras al tranco, hasta que el jinete caía por fin a reir del todo» ${ }^{29}$.

De manera inteligente, Quiroga introduce períodos de tregua en semejante existencia: dos o tres veces al año el Dr. Else recibía la visita de una hija, presuntamente adoptada, durante las cuales se abstenía de beber. En esta muchacha, delgada, vestida siempre de negro, de aspecto enfermizo y mirar hosco, como se nos informa, se va a anudar el trágico final de la narración. En efecto, el empeño del manco llegó a producir vino de naranja que le permitiría obtener un alcohol que hubiera sido comercializable, de no ser por problemas técnicos y porque la insaciable sed de alcohol de Else le hacía tomarse las muestras que el manco trabajosamente preparaba para enviar a Buenos Aires. En esta fase final de su alcoholismo se produce la última, y fatal, visita

\footnotetext{
27 QUIROGA (1993), p. 683.

QUIROGA (1993), p. 687

29 Quiroga (1993), ibidem.
} 
de la hija. Quiroga va a preparar un desenlace grandioso, en donde incluirá la descripción de un proceso de delirium tremens de una realidad sobrecogedora. La naturaleza tropical prestará también un sombrío marco a la tragedia:

\footnotetext{
«El cielo, denso y lívido, como paralizado de pesadez, no presagiaba nada nuevo, tras mes y medio de sequía. Al llegar la lancha, en efecto, comenzó a llover. La maestrita (...) pisó la orilla chorreante bajo agua; subió bajo agua en el carrito, y bajo agua hicieron con su padre todo el trayecto, a punto de que cuando llegaron de noche al Horqueta no se oía en el solitario pajonal ni un aullido de zorro, y sí el sordo crepitar de la lluvia en el patio de tierra del rancho» ${ }^{30}$.
}

Sin solución de continuidad e intercalando apenas una coma nuestro autor pasa de la descripción del tiempo atmosférico, homogéneo y sin más contenido que la incesante lluvia, al tiempo subjetivo, heterogéneo y alucinado, que el alcohol crea en la imaginación de Else. A la vez comienza a materializarse el presagio deslizado en el párrafo recién citado:

«Llovió toda la noche y todo el día siguiente, sin más descanso que la tregua acuosa del crepúsculo, a la hora en que el médico comenzaba a ver alimañas raras prendidas al dorso de sus manos» ${ }^{31}$.

A partir de este momento el delirio no soltará al protagonista, y la narración entra en un crescendo que se resolverá con la muerte de la hija -y presumiblemente con la de Else- a quien éste confunde con una rata. El pasaje pertinente es resuelto por Quiroga de manera magistral, superponiendo y fundiendo, desde la posición del narrador, la realidad alucinada del alcóholico con la de la hija, que ha venido a perturbar inconscientemente una soledad verdaderamente inmodificable:

«Desde las tinieblas comenzaban ya a asomar el hocico bestias innumerables. Del techo se desprendían cosas que él no quería ver. Todo su terror sudoroso estaba ahora concentrado en la puerta, en aquellos hocicos puntiagudos que aparecían y se ocultaban con velocidad vertiginosa.

Algo como dientes y ojos asesinos de inmensa rata se detuvo un instante contra el marco, y el médico, sin apartar la vista de ella cogió un pesado leño: la bestia, adivinando el peligro, se había ya ocultado.

(...) Un instante, el hombre creyó distinguir entre el crepitar de la lluvia, un ruído más sordo y nítido. De golpe, la monstruosa rata surgió en la puerta, se detuvo un momento a mirarlo y avanzó por fin contra él. Else, enloquecido de terror, lanzó hacia ella el leño con todas sus fuerzas» ${ }^{32}$.

\footnotetext{
30 QUIROGA (1993), p. 692.

31 QUIROGA (1993), ibidem.

32 QUIROGA (1993), p. 693.
} 
Naturalmente, la rata era su hija. La historia se cierra con una catártica escena en la que el perdón implícito de la desdichada no hace sino más que amplificar la desolación del padre. Creyendo enfrentar un monstruo, comete un acto monstruoso. Paradójicamente el retorno al delirio significará un alivio al horrible padecimiento que la toma de consciencia de su acto supuso, y que sólo ha podido expresar con la palabra «hijita», apenas murmurada. El párrafo que cierra la historia deja abiertas dos posibilidades: el derrumbe definitivo del protagonista o su muerte:

\footnotetext{
«El ex-hombre tuvo aún tiempo de dejar caer ambas manos sobre las piernas, en un desplome y una renuncia más desesperados que el más desesperado de los sollozos de que ya no era capaz. Y ante el cadáver de su hija, el doctor Else vió otra vez asomar en la puerta los hocicos de las bestias que volvían a un ataque final» ${ }^{33}$.
}

\section{CONCLUSiOnes}

En estas tres narraciones podemos identificar otras tantas metáforas de la enfermedad: como enigma, soledad y destierro. Quizá deberíamos decir como consumaciones de éstos, pues la armonía interna que exhiben hace que la distancia entre la metáfora y lo metaforizado sea prácticamente nula. En «Los buques suicidantes» los términos cuasi-médicos utilizados para explicar la extraña conducta de los marineros suicidas son perfectamente aplicables a las mismas naves, por así decirlo. Podemos predicar de ellos, también, un estado de sonambulismo moroso o muerte hipnótica sin violentar el texto. Con estos dos estados de consciencia, que no son en sí mismos nada espectaculares, Quiroga nos introduce en lo enigmático, en lo desconocido, que tradicionalmente ha estado asociado a la alteración mental. Justamente, lo que provoca extrañeza y temor ante el alienado, es que para nuestra percepción primaria no tiene nada en el cuerpo que indique enfermedad, sino que un aspecto de su persona (el comportamiento) está alterado. Los marineros parecen estar en sus cabales...no obstante se arrojan al agua, uno a uno. Y Quiroga hace aún más; el personaje que relata la historia debe explicar cómo pudo eludir ésta, y con ello se nos muestra en qué consiste la literatura -en realidad todo arte-: en mostrar y ocultar, a la vez, aquello que quiere ser mostrado, pues la explicación es dudosamente verosímil.

Otra es la actitud de Subercasaux. En esta narración, el contexto en el que irrumpe la enfermedad es de lucha y resistencia. Pero desde el momento en que la soledad que atraviesa la narración es una soledad en cierto modo buscada, la lucha es consigo mismo, por imponerse una extrema instalación en el mundo. En efecto, la deliberadamente idílica descripción de la vida que el protagonista y sus pequeños hijos llevan, es puesta en entredicho a partir de un hecho tan trivial como es quedarse sin

\footnotetext{
33 QUiROGA (1993), p. 694
} 
asistenta. Esta situación adquiere una importancia decisiva desde que es la deseperada busca de una reemplazante la que producirá, accidentalmente, la fatal complicación en su pie infectado. Quiroga nos hace ver aquí que bajo determinadas condiciones de vida, el menor percance pone de relieve, por oposición, la aplastante dureza de la vida en el monte. En sí mismo, éste no es ni bueno ni malo, sino que es nuestro destino el que lo transforma. Precisamente, el centro de gravedad de la narración parece estar en la reflexión que el propio Subercasaux hace, ante la infección inicial, (como vimos en el párrafo transcrito más arriba) acerca de condiciones de vida y procesos morbosos. Además, este último es descrito con lo que podríamos llamar un rigor fenomenológico extraordinario, que no hace más que resaltar el desamparo en el que el protagonista enfrentará a la muerte y a la perspectiva de dejar a sus hijos en el abandono más completo. Paradójicamente, lo que le mata no es tanto la complejidad y exuberancia de la selva - de la que es tópico decir que abunda en peligros- sino el desierto en el que se ha convertido su vida y que no por azar da título a la historia.

De manera complementaria la tragedia que envolverá al Dr. Else puede leerse como el triunfo de la selva elemental, contra la que nada podrán las certidumbres de la sabiduría moderna, científica, con la que había sido dotado en su país de origen. Pagará «al país tropical el pesado tributo que quema como en alcohol la actividad de tantos extranjeros.» El vacío que provoca el movimiento de huída del mundo burgués e ilustrado del que parecen provenir esos desdichados (también es la situación del químico Rivet ) es llenado por el alcohol, (mejor, por el alcoholismo). Pero a diferencia del Hans Castorp de «La montaña mágica», la enfermedad no los redime, ni es la ocasión para encontrar un sentido más elevado de la vida. Por el contrario no hace más que degradarlos e infantilizarlos (recuérdese el orgullo que Else sentía por su bastón) hasta convertirlos en ex-hombres, en desterrados en un destierro más existencial y esencial que físico. Aún quienes se han salvado del alcohol tampoco son seres íntegros. En el personaje del manco Luisser (un migrante interno, según nos informa Quiroga al introducirlo en la narración, y que ha perdido el brazo en Buenos Aires) la integridad psíquica y el temperamento creativo y emprendedor que exhibía se compensa con la falta del miembro. El alcoholismo es el último significado que Else ha hallado para su existencia, apenas balanceado por el afecto a la hija adoptiva, y que no podrá superar a aquél.

La alteración mental que desencadena el alcoholismo parece provenir del fondo mismo de su ser y presenta una consistencia ontológica. Por el contrario, la infección que provocará el delirio de Subercasaux parece provenir de fuera del mismo. Lo mismo podríamos postular para la locura colectiva que arrojaba al agua a los desdichados marineros. Pero -y esto es lo que permite la literatura- las tres historias testimonian la dimensión trágica de la vida.

Se nos permitirá concluir, entonces, que en las dos primeras narraciones, especialmente, la fatalidad es un momento más de una misma realidad, una forma extrema de expresarse, pero nada más. Aunque trágica, no es contradistinta de lo que le 
antecede o le sucede. Por eso Subercasaux no está en condiciones de evitar las complicaciones de su infección, ni Else puede evitar confundir a su hija con una rata, o los marineros echarse al agua. Lo que sucedió, y ahí está la genialidad de Quiroga, no podría no haber sucedido, sea lo que sea lo que signifique. Queda por ver si la validez de esta aproximación se confirma en el resto de la narrativa quiroguiana.

\section{BIBLIOGRAFÍA}

Ofrecemos una apretada lista de trabajos sobre Horacio Quiroga. Para consultar su narrativa completa remitimos a la edición crítica de Napoleón Baccino Ponce de León y Jorge Lafforgue citada en nota 2.

Amorim, E. (1983), El Quiroga que yo conocí, Montevideo, Arca, Calicanto.

Baccino Ponce De LeOn, N. (1979) Horacio Quiroga. Itinerarios, Montevideo, Biblioteca Nacional.

Bratosevich, N. (1975), El estilo de Horacio Quiroga en sus cuentos, Madrid, Gredos.

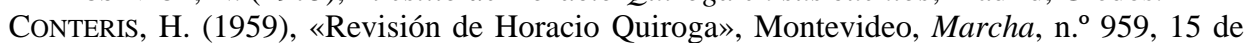
mayo.

CRISAFIO, R. (1983) «Horacio Quiroga o el destierro de la memoria», Milano, Studi di letteratura ispano-americana, . $^{\circ} 13-14$.

Crown, J. (1939) «La locura de Horacio Quiroga», México, Revista Iberoamericana, año 1, n. ${ }^{\circ} 1$.

Delgado, J. y Brignole, A. (1939), Vida y obra de Horacio Quiroga, Montevideo, Claudio García.

EsPINOZA, E. (1937), «Notas sobre la narrativa de Horacio Quiroga», La Habana, Revista cubana, t. 10, n・ 28-30.

ETCHEVERRY, J. (1957) Horacio Quiroga y la creación artística, Montevideo, Facultad de Humanidades y Ciencias, Depto. de Literatura Iberoamericana.

Flores, A. (1976) Aproximaciones a Horacio Quiroga, Caracas, Monte Avila, (este volumen recoge trabajos de varios autores sobre Quiroga).

Garet, L. (1978), Obra de Horacio Quiroga, Montevideo, Ministerio de Educación.

JITRIK, N. (1967) Horacio Quiroga, una obra de experiencia y riesgo, Montevideo, Arca.

MartineZ, J. (1982), Horacio Quiroga. Teoría y práctica del cuento, Xalapa, Universidad Veracruzana.

Martinez Estrada, E. (1966), El hermano Quiroga, Montevideo, Arca.

Monterroso, A. (1983), «Las muertes de Horacio Quiroga», en La palabra mágica, México, Ed.Era.

ORgAmbide, P. (1954), Horacio Quiroga. El hombre y la obra, Buenos Aires, Stilcograf.

Rodriguez Monegal, E. (1968), El desterrado, vida y obra de Horacio Quiroga, Buenos Aires, Losada. 